\title{
Formation of Aromatic Compounds as Side Reactions in the Polycondensation of Bis(2-hydroxyethyl) Terephthalate
}

\author{
Hiroyoshi KAMATANI and Katsuaki KUZE \\ Katata Research Center, Toyobo Co., Ltd. \\ 1300-1 Honkatata, Otsu 520-02, Japan.
}

(Received April 20, 1979)

\begin{abstract}
Studies on the side reactions in the polycondensation of bis(2-hydroxyethyl) terephthalate were performed in the presence of catalysts ( $\mathrm{Mn}, \mathrm{Co}, \mathrm{Zn}, \mathrm{W}) .4,4^{\prime}$ Biphenyldicarboxylic acid, 1,2-bis(4-carboxyphenyl)ethane, and 2,4',5-biphenyltricarboxylic acid were found as major aromatic by-products in the reaction. The yield of these by-products was very poor in the absence of these catalysts, and remarkably increased in the presence of catalysts in the following order: $\mathrm{Mn}<\mathrm{Co}<\mathrm{Zn} \ll \mathrm{W}$. This order was in accord with that of the activity of catalysts for polycondensation of bis(2-hydroxyethyl) terephthalate. The side reactions were suppressed with the addition of radical inhibitor, indicating that the side reactions occurred with a radical mechanism; this was supported from ESR studies. The side reactions are probably initiated by the alkyl radical $\left(\sim \mathrm{C}_{6} \mathrm{H}_{4} \mathrm{COOC}_{2} \mathrm{H}_{4} \cdot\right)$ obtained from the reaction of bis(2-hydroxyethyl) terephthalate with the metal of catalysts.
\end{abstract}

KEY WORDS Bis(2-hydroxyethyl) Terephthalate / Poly(ethylene terephthalate) / Polycondensation / 4,4'-Biphenyldicarboxylic Acid / 1,2-Bis(4carboxyphenyl)ethane / 2,4',5-Biphenyltricarboxylic Acid / ESR / Free

Several side reactions such as etherification ${ }^{1.2}$ and thermal degradation ${ }^{3-6}$ have been observed in the polycondensation of bis(2-hydroxyethyl) terephthalate (BHET) or its oligomer. We found that $4,4^{\prime}-$ biphenyldicarboxylic acid, 2,4',5-biphenyltricarboxylic acid, and 1,2-bis(4-carboxyphenyl)ethane were obtained as by-products in the polycondensation of BHET. The side reactions sometimes lead to the deterioration of the physical and chemical properties of the poly(ethylene terephthalate) (PET) obtained. ${ }^{2.3 .7}$ In order to manufacture PET of high quality, details of the side reactions in the polycondensation must be investigated.

One of the present authors previously identified the mechanism of the polycondensation of BHET in the presence of catalysts $(\mathrm{Co}, \mathrm{Mn}, \mathrm{Zn}){ }^{8}$ In this research, aromatic compounds formed by the side reactions in the polycondensation of BHET were determined quantitatively in the presence of a catalyst ( $\mathrm{Mn}, \mathrm{Co}, \mathrm{Zn}, \mathrm{W})$; the mechanisms for the side reactions are discussed here.

\section{EXPERIMENTA.L}

\section{Materials}

BHET was prepared by the reaction of terephthalic acid with ethylene oxide. ${ }^{9}$

Catalysts (commercially available guaranteed grade) and a radical inhibitor, 1,3,5-trimethyl-2,4,6tris (3,5-di-tert-butyl-4-hydroxybenzyl)benzene (Ionox 330, Shell Fine Chemicals), were used without further prufication.

\section{Polycondensation of BHET}

Polycondensation of BHET $(1.5 \mathrm{~mol})$ was carried out in a $1.0 \mathrm{dm}^{3}$ autoclave in the presence of a catalyst $(0.3 \mathrm{mmol})$ at $273^{\circ} \mathrm{C}$ under reduced pressure. ${ }^{8}$ Samples for the study of by-products were taken out of the autoclave at regular time intervals ${ }^{8}$ and were subjected to methanolysis.

\section{Thermooxidative Degradation of PET}

The polymer containing a polycondensation catalyst was powdered and heated for $1 \mathrm{~h}$ in an oven at $300^{\circ} \mathrm{C}$ under an air stream ${ }^{4-6}$ and was subjected to 
either methanolysis or measurement of ESR.

\section{Methanolysis of PET}

The polymer $(2 \mathrm{~g})$ was placed in an autoclave containing methanol $\left(50 \mathrm{~cm}^{3}\right)$ and depolymerized by heating at $250^{\circ} \mathrm{C}$ for $6 \mathrm{~h}$. The methanol solution was concentrated to about $10 \mathrm{~cm}^{3}$ and was allowed to crystallize out to pure dimethyl terephthalate. The filtrate was further concentrated to dryness. The residue was then dissolved in chloroform $\left(1 \mathrm{~cm}^{3}\right)$, and the solution was analyzed by gas chromatography. ${ }^{5.6}$

\section{Analysis of By-Products}

The gas chromatographic analysis were performed on an Hitachi Model 630 gas chromatograph with a flame ionization detector at $280^{\circ} \mathrm{C}$. A $3 \mathrm{~m} \times 3 \mathrm{~mm}$ column packed with $10 \%$ Apiezon $\mathrm{L}$ oil on Chromosorb W (60/80 mesh) was used. ${ }^{5.6}$ The quantity of by-products was calculated from the peak areas of the gas chromatograms on the basis of the calibration curve which was previously determined.

Mass spectra were measured by using a Hitachi gas chromatograph-mass spectrometer Model RMU-6L.

The ESR measurements were made using a Japan Electron Optics Model JES-FE1X ESR spectrometer with $100 \mathrm{kHz} \mathrm{s}^{-1}$ modulations at room temperature. Each specimen for the ESR study was prepared by polycondensation of BHET in an ESR sample tube $(5 \mathrm{~mm}$ diameter $)$ at $273^{\circ} \mathrm{C}$ under reduced presure, followed by rapid quenching to liquid nitrogen temperature.

\section{Preparation of Authentic Samples}

Dimethyl 4,4'-biphenyldicarboxylate (I) was prepared by the esterification of 4,4'-biphenyldicarboxylic acid with methanol according to the method of Spanninger, ${ }^{6} \mathrm{mp} 218^{\circ} \mathrm{C}$ (lit. ${ }^{6} \mathrm{mp} 216$ $218^{\circ} \mathrm{C}$ ).

Trimethyl 2,4',5-biphenyltricarboxylate (II) was prepared according to the method of Nealy and Adams, ${ }^{5} \mathrm{mp} 107^{\circ} \mathrm{C}$ (lit. ${ }^{5} \mathrm{mp} 105-108^{\circ} \mathrm{C}$ ).

1,2-Bis(4-methoxycarbonylphenyl)ethane was prepared as follows: 1,2-bis(4-carboxyphenyl)ethylene was esterified with methanol according to the procedure of Spaninger. ${ }^{6}$ The products were recrystallized from acetic acid, $\mathrm{mp} 227-228^{\circ} \mathrm{C}$ (lit. ${ }^{10}$ $\left.\mathrm{mp} 227-228^{\circ} \mathrm{C}\right)$. A mixture of 1;2-bis(4-methoxy- carbonylphenyl)ethylene $(4.4 \mathrm{~g}, 0.015 \mathrm{~mol}), 0.2 \mathrm{~g}$ of palladium on carbon, and $150 \mathrm{~cm}^{3}$ of glacial acetic acid was placed in a $500 \mathrm{~cm}^{3}$ autoclave. The autoclave was evacuated and hydrogen was introduced until the pressure was 3 atmosphere. The mixture was shaken at $80^{\circ} \mathrm{C}$ until $0.015 \mathrm{~mol}$ of hydrogen has been absorbed. The catalyst was filtered off and the solvent was removed from the filtrate by distillation. A crude product was recrystallized from methanol, mp $119^{\circ} \mathrm{C}$ (lit. ${ }^{11} \mathrm{mp} 119^{\circ} \mathrm{C}$ ).

\section{RESULTS AND DISCUSSION}

\section{Identification of By-Products}

In order to identify the by-products in the polycondensation of BHET, PET specimens which were polymerized by several kinds of catalysts were depolymerized by heating with an excess of methanol at $250^{\circ} \mathrm{C}$ for $6 \mathrm{~h}$. Figure 1 shows a typical example of the gas chromatogram of methanolyzed PET.

Beside dimethyl 4,4'-biphenyldicarboxylate (I) and trimethyl 2,4',5-biphenyltricarboxylate (II), which were already found in the thermooxidative degradation of PET, ${ }^{6}$ 1,2-bis(4-methoxycarbonylphenyl)ethane (III) was found in the polymerization of BHET.

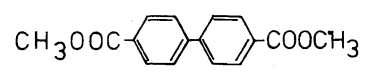

( I )

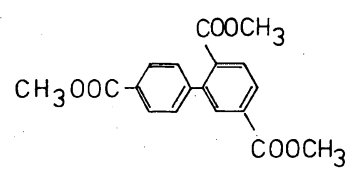

( II)

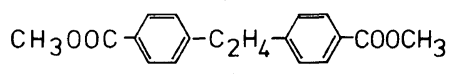

(III)

These by-products (compound I, II; III) were identified by comparing the retntion times of their gas chromatograms and the $m / e$ values of their mass spectra with those of authentic samples.

\section{Effects of Catalysts on the Side Reactions}

Figure 2 shows the time-conversion curves of the 


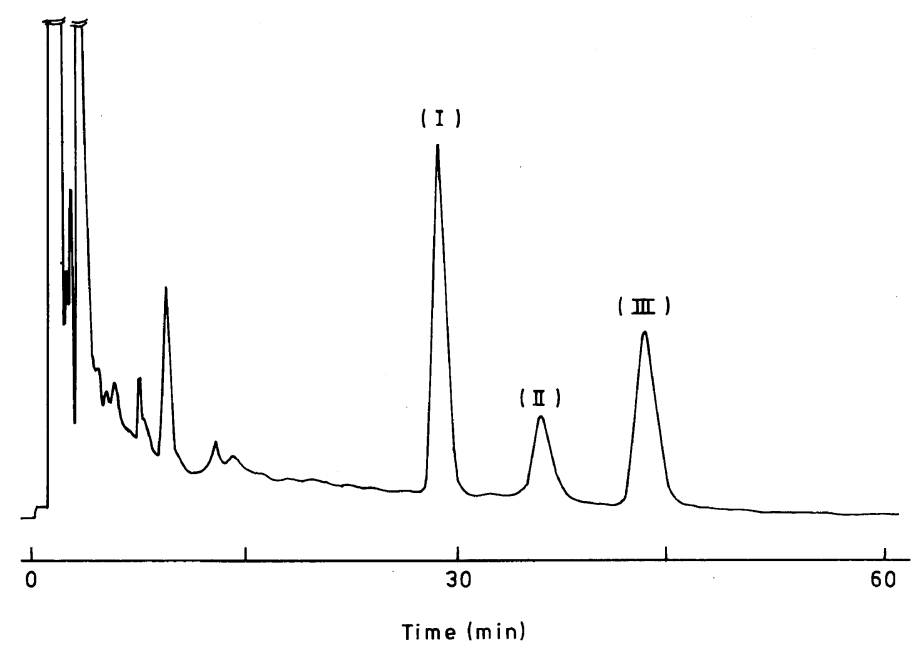

Figure 1. Gas chromatogram of methanolyzed PET: (I), dimethyl 4,4-biphenyldicarboxylate; (II), trimethyl 2,4,'5-biphenyltricarboxylate; (III), 1,2-bis(4-methoxycarbonylphenyl)ethane.

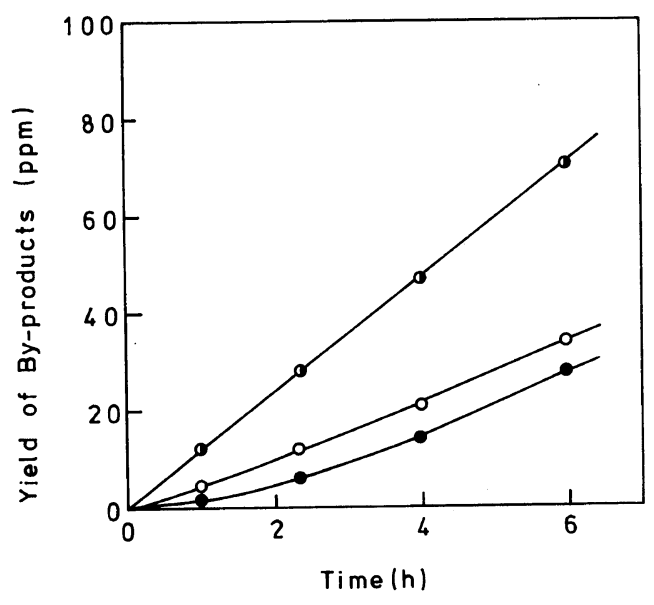

Figure 2. Time-conversion curves of by-products: polycondensation catalyst, $\mathrm{Co}\left(\mathrm{O}_{2} \mathrm{CCH}_{3}\right)_{2} \quad 4 \mathrm{H}_{2} \mathrm{O}, \quad 0.02$ $\mathrm{mol} \%$;, compound (I); O, compound (II); $\bigcirc$, compound (III).

by-products (I, II, III) formed in the polycondensation in the presence of cobalt (II) acetate. Yields of these by-products (I, II, III) increased almost linearly with polycondensation time in the following order: II $<$ III $<$ I.

The effects of various catalysts on the yield of byproducts were shown in Table I.

By-products were scarcely produced in the absence of catalysts, and increased with the addition of catalysts. The activity of catalysts for the side reactions increased in the following order: $\mathrm{Mn}<\mathrm{Co}<\mathrm{Zn} \ll \mathrm{W}$. The order was in accord with that of activity of catalysts for the polycondensation of BHET. The activity is indicated in Table I as the intrinsic viscosity of PET.

Since the catalytic polycondensation of BHET proceeds with an ionic mechanism, ${ }^{8}$ the side reactions are expected to proceed with an ionic mechanism. However the radical mechanism can not be neglected, ${ }^{12}$ because the polycondensation of BHET was carried out at such a high temperature, $273^{\circ} \mathrm{C}$. In order to clarify which mechanisms may be reasonable to account for the side reactions of BHET, the polycondensation was carried out in the presence of a radical inhibitor, Ionox 330 (Table I). A remakable decrease in the yield of by-products with the addition of the radical inhibitor suggests that the side reactions in the catalytic polycondensation proceed with a radical mechanism. Actually the formation of free radical was observed in an ESR spectrometry of the polycondensation system, as shown in Figure 3.

This free radical seems to be derived from a BHET unit, not from catalyst metal, because the catalyst metal contained in PET gave no detectable ESR spectrum in the region of the measurement.

Since it has been known ${ }^{6}$ that compounds I and II were produced by thermooxidative degradation of PET, it will be necessary to make sure whether these compounds I and II were produced by the thermooxidative degradation caused by trace amounts 
H. Kamatani and K. KuZE

Table I. Effect of catalysts on the yield of by-products

\begin{tabular}{|c|c|c|c|c|c|c|}
\hline \multirow{2}{*}{ Catalyst $^{\mathrm{a}}$} & \multirow{2}{*}{$\frac{\text { Time }^{b}}{h}$} & \multirow{2}{*}{$\frac{\text { Time }^{c}}{h}$} & \multirow{2}{*}{$\frac{[\eta]^{\mathrm{d}}}{100 \mathrm{~cm}^{3} \mathrm{~g}^{-1}}$} & \multicolumn{3}{|c|}{ By-product/ppm } \\
\hline & & & & I & II & III \\
\hline \multicolumn{7}{|l|}{ (Polycondensation) } \\
\hline None & 2 & - & 0.168 & 5 & 0 & 2 \\
\hline $\mathrm{Mn}\left(\mathrm{O}_{2} \mathrm{CCH}_{3}\right)_{2} 4 \mathrm{H}_{2} \mathrm{O}$ & 2 & - & 0.565 & 18 & 4 & 8 \\
\hline $\mathrm{Co}\left(\mathrm{O}_{2} \mathrm{CCH}_{3}\right)_{2} 4 \mathrm{H}_{2} \mathrm{O}$ & 2 & - & 0.739 & 23 & 5 & 10 \\
\hline $\mathrm{Co}\left(\mathrm{O}_{2} \mathrm{CCH}_{3}\right)_{2} 4 \mathrm{H}_{2} \mathrm{O}$ & 4 & - & 0.849 & 47 & 14 & 21 \\
\hline $\mathrm{Zn}\left(\mathrm{O}_{2} \mathrm{CCH}_{3}\right)_{2} 2 \mathrm{H}_{2} \mathrm{O}$ & 2 & - & 0.776 & 28 & 7 & 11 \\
\hline $\mathrm{H}_{2} \mathrm{WO}_{4}$ & 4 & - & 1.497 & 234 & 152 & 230 \\
\hline $\mathrm{H}_{2} \mathrm{WO}_{4}$-Inonx 330 & 4 & - & 1.482 & 68 & 34 & 61 \\
\hline \multicolumn{7}{|l|}{$\begin{array}{l}\text { (Thermooxidative } \\
\text { degradation) }\end{array}$} \\
\hline $\mathrm{Co}\left(\mathrm{O}_{2} \mathrm{CCH}_{3}\right)_{2} 4 \mathrm{H}_{2} \mathrm{O}$ & 4 & 1 & - & 1,380 & 10,300 & 30 \\
\hline $\mathrm{H}_{2} \mathrm{WO}_{4}$ & 4 & 1 & - & 1,490 & 11,100 & 42 \\
\hline
\end{tabular}

a Catalyst, $0.2 \mathrm{mmol} / \mathrm{mol}$ BHET. ${ }^{b}$ Polycondensation time. ${ }^{\mathrm{c}}$ Thermooxidative degradation time. ${ }^{\mathrm{d}}$ Intrinsic viscosity of PET.

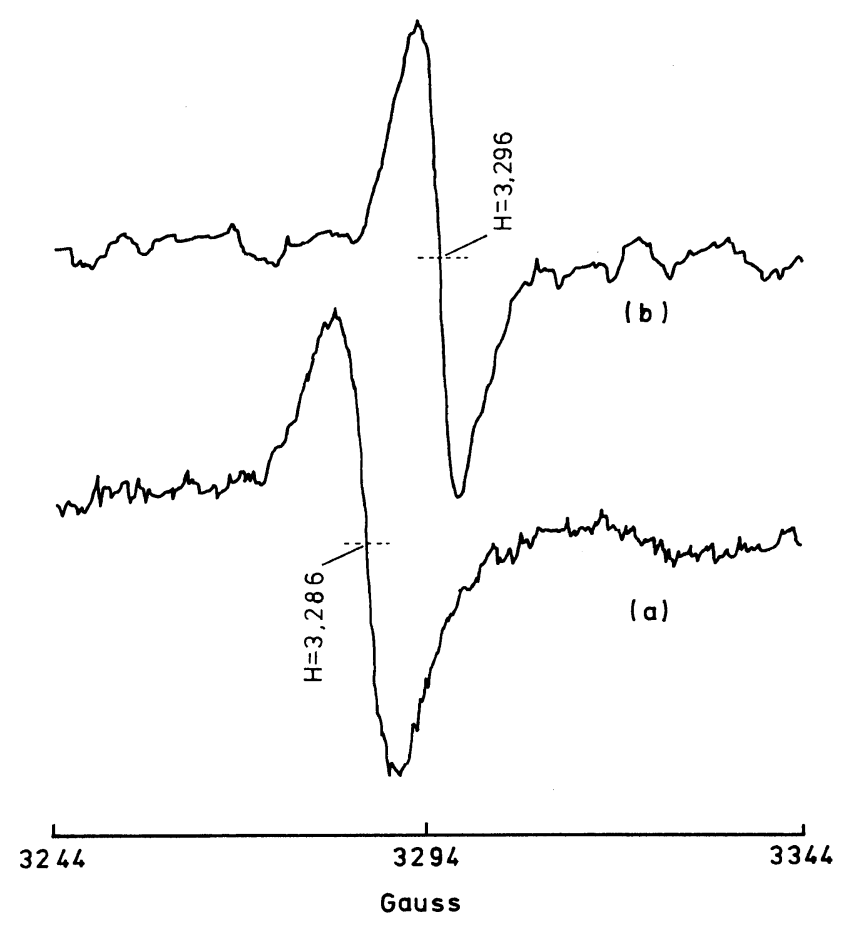

Figure 3. ESR spectra of PET (a) and thermooxidatively degraded PET (b).

(a): EPT (a) obtained by the polycondensation of BHET in the presence of $\mathrm{H}_{2} \mathrm{WO}_{4}$ for $4 \mathrm{~h}$.

(b): PET (b) prepared by heating the PET (a) at $300^{\circ} \mathrm{C}$ for $1 \mathrm{~h}$ under an air stream.

of oxygen in the polycondensation system. Compounds I, II, and III in the thermooxidative degradation were confirmed to be the same com- pounds as those found in the catalytic polycondensation and their yields were determined quantitatively. These results are also shown in Table I. The 
yields of these compounds in the thermooxidative degradation were in the following order: $\mathbf{I I I} \ll \mathbf{I} \ll \mathbf{I I}$; this order is not in accord with that of the byproducts in the catalytic polycondensation. These results indicate that the side reactions in the polycondensation proceeded with a radical mechanism which was different from the radical mechanism in the thermooxidative degradation of PET. The difference of mechanism in the two reactions is also evident from the fact that the ESR signal $(\mathrm{H}=3,286$ gauss) of free radicals found in the catalytic polycondensation was different from that ( $\mathrm{H}=3,296$ gauss) in the thermooxidatively degraded PET (Figure 3).

\section{Mechanism of Side Reactions}

The fact that the activity of catalyst for these side reactions was parallel to that for the cataltic polycondensation leads to the assumption that the side reactions are caused by the same intermediate as the catalytic polycondensation of BHET. ${ }^{8}$

Since it has been shown ${ }^{8}$ that the rate of catalytic polycondensation increased with increasing electron density on the hydroxyl group (the end group of the polymer) due to back donation from the metal in complex IV, the side reaction would also be correlated with electron density on the hydroxyl group. Accordingly, the side reactions would possibly be initiated by the thermal decomposition of complex IV accompanying electron transfer from the metal to ligand, as shown in eq $1 .^{13}$ Thermal decomposition of an alkyl-oxygen bond (eq 1) seems to be reasonable in our experimental condition of $273^{\circ} \mathrm{C}$, because evolution of water has been observed even in the distillation of 2-hydroxyethyl benzoate at $146^{\circ} \mathrm{C} / 3$ $\mathrm{mmHg}(0.4 \mathrm{kPa}){ }^{14}$

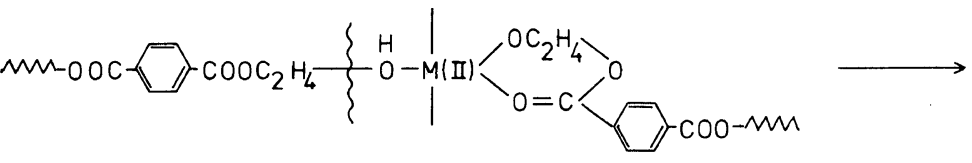

(IV)

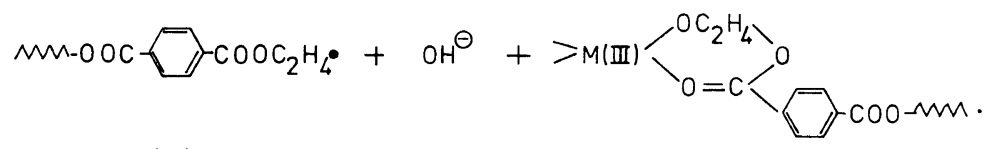

( V)

( VI)

$$
\text { (VI) }
$$

[Path 1]

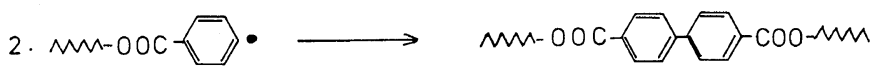


[Path 2]

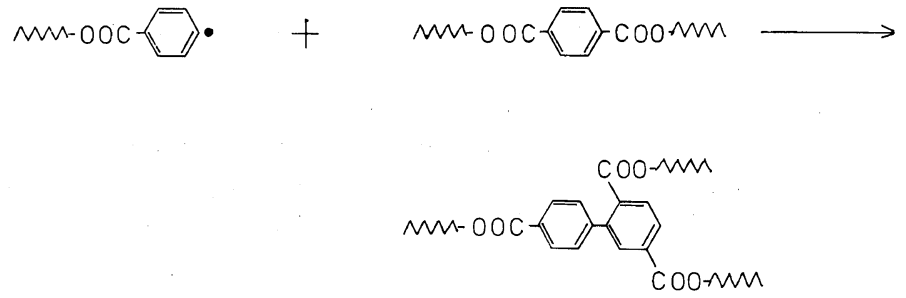

(II)

Increase of the positive charge of the metal in complex VI enhances the coordination ability of 2alkoxyethyl ester to the catalyst metal. ${ }^{15,16}$ As a result the thermal decomposition of the alkyloxygen bond of 2-alkoxyethyl ester would be accelerated (eq 3). ${ }^{17}$ For the phenyl radical, which was formed by the thermal decomposition of complex VI, followed by decarboxylation ${ }^{6}$ (eq 4), two pathways of reaction are avaiable. ${ }^{6}$ Path 1 is a simple coupling of two phenyl radicals to give the 4,4'biphenyldicarboxylic acid derivative (I) (eq 5), which was the most abundant by-product in the polycondensation. In path 2, the phenyl radical attacks the aromatic ring in the polymer to give the $2,4^{\prime}, 5$ biphenyltricarboxylic acid derivative (II), as shown in eq 6.

The formation of the 1,2-bis(4-carboxyphenyl)ethane derivative (III) would be explained as follows. Radical $\mathbf{V}$ formed in equation 1 would further thermally decompose to radical VII (eq 7), which in turn couples with the phenyl radical to give the 1,2bis(4-carboxyphenyl)ethane derivative (III) (eq 8). The direct decarboxylation of ester is very rare, but has been shown to occur in the pyrolysis of vinyl benzoate to styren $\mathrm{e}^{17}$ or in the photolysis of PET. ${ }^{3}$

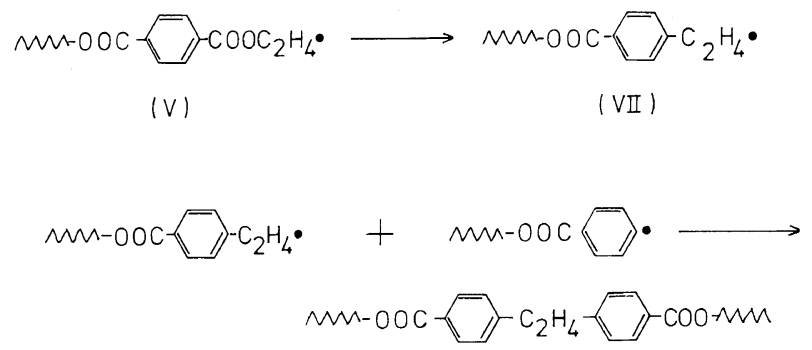

(III)

Although the mechanism of polycondensation of BHET in the presence of tungsten catalyst is not clear, it would be possible to assume a complex similar to that of $\mathrm{Mn}, \mathrm{Co}$, and $\mathrm{Zn}$, because tungsten is also a transition metal and is able to make a complex with $\mathrm{OH}$-groups of alcohol. ${ }^{18.19}$

Acknowledgement. The authers wish to express their sincere thanks to Professor S. Nozakura and Associate Professor M. Kamachi of Osaka University for reading this manuscript and giving much kind advice, and for measuring the ESR sepctra. They also thank Mr. M. Tahara, director and general manager of the Development and Research Center, Toyobo Co., Ltd., for permission to publish this work.

\section{REFERENCES}

1. S. G. Hovenkamp and J. P. Munting, J. Polym. Sci., A-1, 8, 679 (1970).

2. H. R. Penton, Jr. and H. Bouman, Polym. Prepr., Am. Chem. Soc., Div. Polym. Chem., 17, 521 (1976).

3. L. H. Buxbaum, Angew. Chem. Int. Ed., 7, 182 (1968).

4. K. Yoda, A. Tsuboi, M. Wada, and R. Yamadera, J. Appl. Polym. Sci., 14, 2357 (1970).

5. D. L. Nealy and L. J. Adams, J. Polym. Sci., A-1, 9, 2063 (1971). 
6. P. A. Spanninger, J. Polym. Sci., Polym. Chem. Ed., 12, 709 (1974).

7. J. R. Kirby, A. J. Baldwin, and R. H. Heidner, Anal. Chem., 37, 1306 (1965).

8. H. Kamatani and S. Konagaya, Kobunshi Ronbunshu, 35, 787 (1978).

9. H. Kamatani, Nippon Kagaku kaishi, 1505 (1977).

10. G. P. Hager, A. M. VanArendonk, and H. A. Shonle, J. Am. Chem. Soc., 66, 1982 (1944).

11. C. Liebermann, Ber., 45, 1186 (1912).

12. E. M. Bilger and H. Hibbert, J. Am. Chem. Soc., 58, 823 (1936).

13. D. R. Eaton and S. R. Suart, J. Phys. Chem., 72, 400
(1968).

14. H. V. R. Iengar and P. D. Ritchie, J. Chem. Soc., 2556 (1957).

15. M. Munakata, M. Matsui, M. Tabushi, and T. Shigematsu, Bull. Chem. Soc. Jpn., 43, 114 (1970).

16. R. Steinberger and F. H. Westheimer, J. Am. Chem. Soc., 73, 429 (1951).

17. R. J. P. Allan, R. L. Forman, and P. D. Ritchie, $J$. Chem. Soc., 2717 (1955).

18. M. Mugdan and D. P. Young, J. Chem. Soc., 2988 (1949).

19. E. S. Gould, R. R. Hiatt, and K. C. Irwin, J. Am. Chem. Soc., 90, 4573 (1968). 